\title{
Attenuation of response deficits by electroconvulsive shock
}

\author{
P. L. LAMBERT and E. H. HARRELL \\ North Texas State University, Denton, Texas 76203
}

and

\author{
M. W. EMMETT-OGLESBY \\ Department of Pharmacology, North Texas State University, Texas College of Osteopathic Medicine \\ Fort Worth, Texas 76107
}

\begin{abstract}
Rats previously exposed to inescapable footshock were inferior to nonshocked rats in acquiring a shock-escape response. In three separate experiments, these response deficits were improved by electroconvulsive shock (ECS) given $1 \mathrm{~h}$ prior to testing. Subsequent experiments suggested that this effect cannot be attributed to ECS-induced (1) retrograde amnesia, (2) decreased shock thresholds, or (3) increased general activity.
\end{abstract}

Exposure to inescapable aversive events produces response deficits. For example, dogs given inescapable electric footshock subsequently fail to acquire an escape-avoidance response (Overmier \& Seligman, 1967; Seligman \& Maier, 1967); rats exposed to a prolonged forced-swimming procedure subsequently are immobile (Weiss, Stone, \& Harrell, 1970). Other response deficits have been produced by a variety of inescapable aversive events (Altenor, Kay, \& Richter, 1977; Hiroto \& Seligman, 1975), and the phenomenon has been extended across several species, including man (Benson \& Kennelly, 1977; Braud, Wepman, \& Russo, 1969; Maier \& Testa, 1975; Overmier, 1968; Padilla, 1973; Welker, 1976).

Electroconvulsive shock (ECS) has been used to attenuate the response deficits produced by inescapable aversive events. Dorworth and Overmier (1977) reported that multiple ECS improved performance that had been impaired by exposure to inescapable footshock. However, they did not report significant differences between ECS and no-ECS groups, but found significant improvement only across trials within the ECS group. In addition, they did not test the possibility that ECS produced retrograde amnesia for the inescapable shock. Therefore, the present experiments were designed to examine the effect of ECS on the response deficit produced by inescapable footshock. Additional experiments tested whether

This project was supported by North Texas State University Faculty Research Grant 34687. Requests for reprints should be sent to M. W. Emmett-Oglesby, Department of Pharmacology, Texas College of Osteopathic Medicine, Camp Bowie at Montgomery, Fort Worth, Texas 76107. We gratefully acknowledge the technical assistance of Jana Jordan and Dwight Ivey. We thank Ann Brewin and F. Gage for their comments on the manuscript. memory disruption, altered shock thresholds, or increased general activity might account for this effect.

\section{EXPERIMENT 1}

Experiment 1 was intended to replicate the observation that rats subjected to inescapable footshock show subsequent response deficits as compared to nonshocked controls.

\section{Method}

Subjects. Twenty-four male Sprague-Dawley albino rats (ARS, Madison, Wisconsin), 60 days old at the beginning of the experiment, served as subjects. The subjects in this experiment and in all subsequent experiments were housed individually and maintained ad lib on food and water throughout the experiment.

Apparatus. All training and testing were conducted in a modified shuttlebox (Model RSC-044, BSR/LVE) with a floor of 3/32" stainless steel rods through which electric shock could be delivered by a constant shock generator (Model SGS 003, BRS/LVE). A partition divided the shuttlebox into two chambers, each $43 \mathrm{~cm}$ long $\times 20 \mathrm{~cm}$ wide $\times 24 \mathrm{~cm}$ deep. During training, an omnidirectional pole (Model 16069, Gerbrands Co.) was suspended from the ceiling into one of the two chambers. A 3.2-mm-diam screw attached at the bottom of the pole projected $6 \mathrm{~cm}$ horizontally into the center of that chamber. During testing, a lever (Model G6-312, Gerbrands Co.) mounted to an end wall projected $3.2 \mathrm{~cm}$ into one of the chambers. All training and testing contingencies were controlled with combinations of BRS/LVE solid state and electromechanical programming equipment.

Procedure. In the induction phase, eight rats were assigned randomly to each of three conditions: escapable shock (E), inescapable shock (I), or no shock (NS). Each rat from Group E was paired randomly with a rat from Group I, and the $E$ and I pairs were placed in the shuttlebox with the $\mathrm{E}$ animal in the compartment that contained the omnidirectional pole. The yoked pair received 90 trials of $2-\mathrm{mA}$, unsignaled, pulsating footshock $(.5 \mathrm{sec}$ on, $.5 \mathrm{sec}$ off) delivered on a variable intertrial interval with a mean of $90 \mathrm{sec}$ and minimum duratior. of $30 \mathrm{sec}$. During the first 30 trials, rats in Group E were shaped to push the pole to terminate shock for the pair. During the next 30 trials, a single pole-push 
$1 \mathrm{~cm}$ in the horizontal plane terminated shock, and during the final 30 trials, two pole pushes (FR 2) were required to terminate shock. Each rat in Group NS was placed in the chamber for the same length of time as the $E$ and I pairs, but without shock.

On the day following training, the pole was removed from the chamber and the lever was inserted. Rats from all groups were tested individually on 60 trials of escapable shock terminated by leverpressing on an FR 2 schedule. If, at the end of $60 \mathrm{sec}$, two barpresses did not occur, the trial was terminated automatically. Therefore, a latency of $60 \mathrm{sec}$ indicates failure to escape. The intertrial interval and shock parameters were identical to those used in the induction phase.

\section{Results}

Rats exposed to inescapable shock were inferior in escape responding (Figure 1), as shown by a one-way analysis of variance $(\mathrm{F}=5.41, \mathrm{df}=2,21, \mathrm{p}<.05)$. By Newman-Keuls analysis, Group I showed a response deficit $(p<.05)$ when compared to Group NS, whereas Group E did not. Furthermore, Group I had a mean latency of $55.30 \mathrm{sec}$ out of $60 \mathrm{sec}$ possible, indicating nearly complete lack of responding. Because Groups $E$ and $I$ were administered an identical amount of shock, the response deficit in Group I cannot be attributed to shock per se. Thus, Experiment 1 demonstrates that this quantity of inescapable shock is adequate to produce significant response deficits relative to the NS group.

\section{EXPERIMENT 2}

Experiment 2 was designed to determine whether

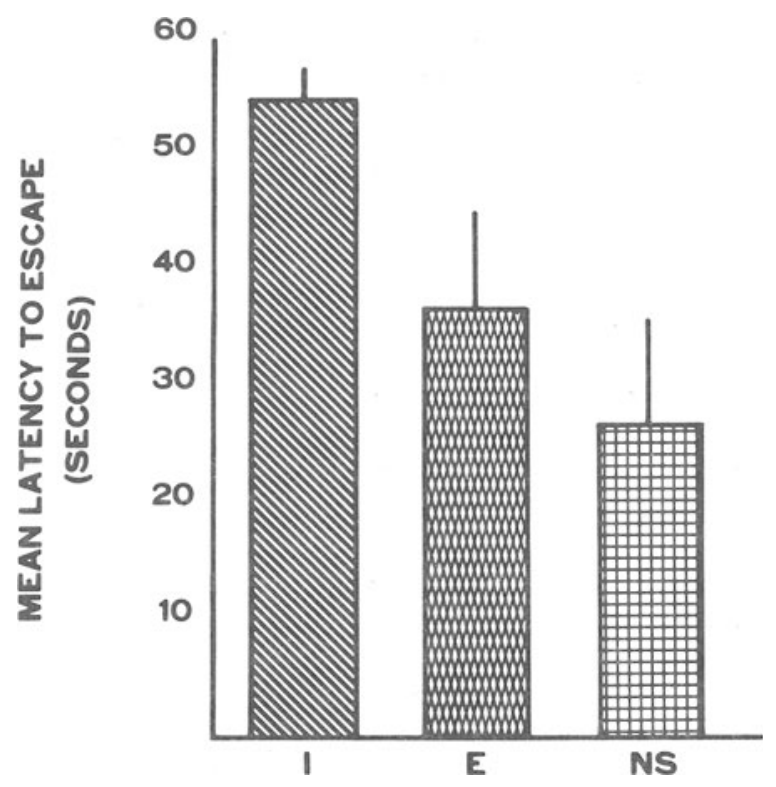

Figure 1. Effect of inescapable footshock induction on mean latencies to escape during testing. Ordinate: mean latency to escape on the FR 2 barpress task. Axis: I = inescapable shock during induction; $\mathbf{E}=$ escapable shock during induction; $\mathbf{N S}=$ no shock during induction. Lines above bars show standard errors of the mean. electroconvulsive shock would improve performance in rats previously subjected to inescapable footshock.

\section{Method}

Subjects. Thirty-two, 60-day-old, male Sprague-Dawley (ARS) rats served as subjects.

Apparatus. A Lafayette A-615B electroconvulsive shocker was employed to deliver ECS (Lafayette Instrument Co.). Induction and testing were conducted in the same apparatus utilized in Experiment 1.

Procedure. Eight rats were assigned randomly to each of four groups: (1) inescapable shock (I), (2) inescapable shock and electroconvulsive shock (I/ECS), (3) no shock (NS), and (4) no shock and electroconvulsive shock (NS/ECS). During training, rats from Group I were paired randomly with rats from group I/ECS. Each pair was placed in adjacent compartments of the shuttlebox and given 90 trials of unsignaled, pulsating, inescapable shock. Programming of intertrial interval and shock parameters was identical to that in Experiment 1. During the first 10 trials, shock duration for the pair was $60 \mathrm{sec}$; during the second 10 trials, shock duration was $15 \mathrm{sec}$; and during the remaining 70 trials, shock duration was $5 \mathrm{sec}$. These parameters were selected by approximating the average duration of shock that the yoked pairs received during the first 10 , second 10 , and final 70 trials of induction in Experiment 1. Thus, this procedure equated quantity of shock across all subjects in the I and I/ECS groups. Rats in Groups NS and NS/ECS were paired randomly and placed in the apparatus for a time comparable to that for the I and I/ECS groups, but received no footshock.

On the day following induction, all rats were tested individually utilizing the FR 2 barpress escape response. Shock parameters and procedures were identical to those used in Experiment 1. One hour prior to testing, each animal was placed under a bell jar and subjected to light ether anesthesia to prevent injury during ECS. Immediately following the loss of the righting reflex, the rat's head was shaved, and alligator clip electodes were fastened to the scalp, medial to each ear. A 50-mA electroconvulsive shock was delivered for $1 \mathrm{sec}$ to animals in Groups I/ECS and NS/ECS. Duration of seizures averaged $19 \mathrm{sec}$, and all rats subjected to ECS showed tonic-clonic convulsions. Group I and NS were subjected to the same procedure, but no current was passed through the electrodes.

\section{Results}

Group I showed the most extreme response deficit, whereas Group I/ECS was closer in performance to the no-shock groups (Figure 2). By a $2 \times 2$ analysis of variance, the main effect of inescapable vs. no shock was significant $(F=5.97, \mathrm{df}=1,28, \mathrm{p}<.05)$, the main effect of ECS vs. no ECS was not significant $(\mathrm{F}<1.00$, df $=1,28, \mathrm{p}>.05)$, and the interaction was nearly significant $(\mathrm{F}=3.59$, df $=1,28, \mathrm{p}<.10)$. By planned comparisons, only Group I was significantly different from Group NS $(\mathrm{F}=9.41$, $\mathrm{df}=$ $1,28, \mathrm{p}<.01)$ and the difference between Group I/ECS and $I$ approached significance $(F=3.01, d f=1,28$, $p<.10)$. The results of this experiment suggest that ECS reverses response deficits induced by inescapable footshock. Group I was inferior to Group NS, whereas Group I/ECS was not inferior to Group NS.

\section{EXPERIMENT 3}

To strengthen the conclusion that electroconvulsive shock reverses response deficits, the I and I/ECS treatment conditions of Experiment 2 were replicated using 


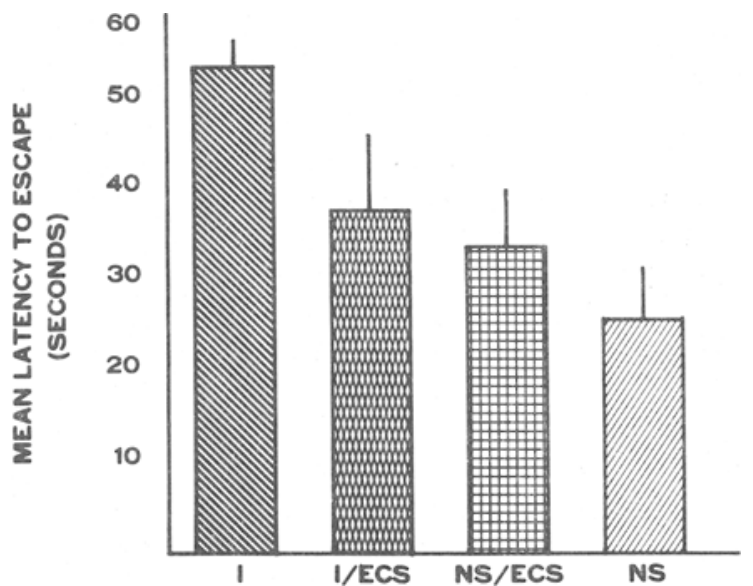

Figure 2. Effect of electroconvulsive shock on escape responding. Ordinate: see Figure 1. Axis: I = inescapable shock during induction; NS = no shock during induction; $\mathbf{E C S}=$ electroconvulsive shock $1 \mathrm{~h}$ pretest. Lines above the bars show standard errors of the mean.

15 subjects per group. Mean latencies \pm S.E.M. to escape shock were $56.0 \pm 1.3 \mathrm{sec}$ for Group I and $43.4 \pm 5.4 \mathrm{sec}$ for Group I/ECS $(\mathrm{t}=2.28, \mathrm{df}=28$, $\mathrm{p}<.05)$. These results confirm that ECS reduces the response deficit produced by exposure to inescapable shock.

\section{EXPERIMENT 4}

In Experiments 1 and 2, the mean latencies to escape shock for the NS control groups were 28.0 and $27.5 \mathrm{sec}$. On the other hand, in Experiment 2, the mean latency for the I/ECS group was $38.3 \mathrm{sec}$, and in Experiment 3 , the mean latency for this group was $43.4 \mathrm{sec}$. Thus, although a 1 -sec ECS facilitated responding, the performance of the I/ECS group was consistently inferior to that of the NS group.

In an attempt to demonstrate the effect more conclusively, the I and I/ECS conditions were replicated using 12 subjects per group and a 2-sec ECS. Results again confirmed that ECS facilitates responding; mean latencies \pm S.E.M. to escape shock were $52.8 \pm 3.7 \mathrm{sec}$ for Group I and 34.3 $\pm 5.4 \mathrm{sec}$ for Group I/ECS $(\mathrm{t}=2.88, \mathrm{df}=22, \mathrm{p}<.01)$. As compared to the mean latency following a $1-\mathrm{sec}$ ECS, the lower mean latency following a 2-sec ECS suggests that the duration of the ECS may be correlated with the degree of improvement in responding.

\section{EXPERIMENT 5}

Electroconvulsive shock has well-documented disruptive effects on memory; therefore, this experiment was intended to determine whether ECS produced retrograde amnesia for events occurring 1 day prior to the test task.
Sixteen rats were trained to escape a 2-mA pulsating footshock using an FR 2 barpress escape response. Ninety trials of shock (same parameters as Experiment 1) were presented in the same apparatus described above. Escape responding was shaped during the first 30 trials; during the next 30 trials, a single barpress terminated shock, and during the final $\mathbf{3 0}$ trials, two barpresses terminated shock. Twenty-three hours after training, the subjects were given either sham ECS or a 2-sec ECS, and $1 \mathrm{~h}$ later, retention of the FR 2 barpress escape response was tested in all subjects. Mean latencies \pm S.E.M. to respond on the first trial was $21.6 \pm 6.9 \mathrm{sec}$ for the ECS group and $23.3 \pm 8.3 \mathrm{sec}$ for the sham-ECS group $(\mathrm{t}=.15$, $\mathrm{df}=14, \mathrm{p}>.05$ ). Thus, these results offer no support for the hypothesis that ECS interferes with the retention of a response learned $23 \mathrm{~h}$ previously.

\section{EXPERIMENT 6}

The possibility that ECS alters reactivity to footshock was tested with 10 rats in each group according to the procedure of Turner, Sechner, and Liebelt (1967) using two observers blind to treatment conditions to rate shock reactivity. A flich was defined as a distinct movement in response to the shock. In a pilot study, no rats responded with a flinch at shock intensities less than .4 mA; therefore, in this experiment, shock intensities ranged from .4 to $2.4 \mathrm{~mA}$ and each value was presented four times in a randomized order. The flinch threshold was defined as the minimum shock value which produced a flinch on $50 \%$ of the presentations of that value. Mean flinch thresholds \pm S.E.M. were $.84 \pm .09 \mathrm{~mA}$ for the group given ECS $1 \mathrm{~h}$ pretest and $.99 \pm .14 \mathrm{~mA}$ for the sham-ECS group $(t=.93, \mathrm{df}=18, \mathrm{p}>.05)$. These data offer no support for the hypothesis that ECS decreases footshock thresholds.

\section{EXPERIMENT 7}

The possibility that ECS improves responding by increasing activity levels was tested by comparing open-field activity in ECS and sham-ECS groups. Using 12 rats per group, the number of 6-in. square crossings during $30 \mathrm{~min}$ in a $2 \times 4 \mathrm{ft}$ box was scored by observers blind to experimental conditions. The mean number of crossing \pm S.E.M. for the group given ECS $1 \mathrm{~h}$ prior to testing was $58.2 \pm 11.98$, and for the group given sham-ECS it was $42.8 \pm 13.55$ $(\mathrm{t}=.88, \mathrm{df}=22, \mathrm{p}>.05)$. Even though the mean number of crossings was higher in the ECS group, the mean difference would be observed frequently by chance alone. Indeed, Porsolt, Anton, Blavet, \& Jalfre (1978) reported that ECS administered $1 \mathrm{~h}$ prior to testing resulted in slightly lower open-field activity, but this effect was not significant. Thus, two studies failed to find any indication that ECS alters general activity. 


\section{GENERAL DISCUSSION}

Previous research by Dorworth and Overmier (1977) and Porsolt et al. (1978) indicates that ECS may reverse response deficits produced by inescapable aversive events. However, Porsolt et al. did not test for deficits using a conditioning procedure but, rather, demonstrated that ECS eliminated immobility produced by forced exposure to water immersion. Dorworth and Overmier did employ a conditioning test task, but they did not report significant differences between the ECS and no-ECS groups, perhaps because they tested a small number of subjects ( $n=6$ in the ECS group, and $n=4$ in the no-ECS group). In the present study, ECS was shown to attenuate the effects of inescapable shock in three separate experiments. Thus, these results demonstrate that ECS attenuates response deficits that have been induced by exposure to inescapable shock.

The behavioral and neural mechanisms through which ECS facilitates responding are unknown, perhaps because most animal studies have focused on adverse effects of ECS such as retrograde amnesia. Indeed, retrograde amnesia may well account for the findings reported by Dorworth and Overmier and Porsolt et al. Both of these studies employed multiple ECS treatments, and, in the Porsolt et al. experiment, the initial ECS was administered $1 \mathrm{~h}$ after exposure to the induction task. Retrograde amnesia frequently occurs when multiple ECS are employed or when a single ECS is used which closely follows a learning task (McGaugh, 1966). The present experiments do not appear to be explained by a retrograde amnesia hypothesis because, typically, a single ECS administered 1 day after learning does not produce retrograde amnesia in rats (Chorover \& Schiller, 1965; Duncan, 1949). As shown in Experiment 5, there is no evidence that memory disruption accounts for the present results.

Although memory mechanisms may not be involved in ECS-facilitated responding, this effect may be a function of altered sensitivity to aversive stimulation or a general motor activation. Experiments 6 and 7 provide no evidence that these effects occur in control animals subjected to ECS; however, the possibility exists of a differential effect of ECS on shock sensitivity or general activity in animals previously subjected to inescapable shock. In addition, Experiment 6 produced flinch thresholds that are higher than those typically reported in the literature. This may, in part, be attributable to our definition of flinch, which required a pronounced movement. These high threshold values may limit the significance of Experiment 6. Nevertheless, changes in shock sensitivity might not be expected to modify response deficits, because increasing or decreasing the footshock during testing does not affect response deficits produced by inescapable shock (Seligman, 1975), and we are unaware of any data demonstrating that ECS alters footshock thresholds. The possibility that ECS produced increased motor activity has been tested by Porsolt et al. (1978). In agreement with the present results, in control rats, ECS did not increase the activity in an open-field test. Their basic finding, that ECS eliminated immobility produced by aversive stimuli, can be described as motor activation; however, Porsolt et al. did not interpret their results within this framework.

The demonstration that ECS is effective in the attenuation of response deficits in animals provides an opportunity for investigating possible neurophysiological and neurochemical mechanisms underlying reinforced responding. For example, there is evidence that reinforced responding and punishment modify brain catecholamine metabolism in opposite directions (Anisman, de Catanzaro, \& Remington, 1978; Emmett-Oglesby, Lewy, Albert, \& Seiden, 1978; Glazer \& Weiss, 1976; Seiden, MacPhail, \& EmmettOglesby, 1975; Weiss, Glazer, \& Pohorecky, 1976; Weiss et al., 1970). The attenuation of response deficits offers a behavioral procedure for testing the role of catecholoamines or other neurochemicals in mediating the effects of ECS, punishment, and negatively reinforced behavior in subjects receiving comparable quantities of aversive stimulation.

\section{REFERENCES}

Altenor, A., Kay, E., \& Richter, M. The generality of learned helplessness in the rat. Learning and Motivation. 1977, 8, 54-61.

Anisman, H., deCatanzaro, D., \& Remington, G. Escape performance following exposure to inescapable shock: Deficits in motor response maintenance. Journal of Experimental Psychology: Animal Behavior Processes, 1978, 4, 197-218.

Benson, J. S., \& Kennelly, K. J. Learned helplessness: The result of uncontrollable aversive stimuli? Journal of Personality and Social Psychology, 1977, 34, 138-145.

Braud, W., Wepman, B., \& Russo, D. Task and species generality of the helplessness phenomenon. Psychonomic Science, $1969,16,154-155$.

Chorover, L., \& Schiller, H. Short-term retrograde amnesia in rats. Journal of Comparative and Physiological Psychology, 1965, 59, 73-78.

Dorworth, T. R., \& Overmier, J. On learned helplessness: The therapeutic effects of electroconvulsive shock. Physiological Psychology, 1977, 5, 355-358.

Duncan, C. P. The retroactive effect of electroshock on learning. Journal of Comparative and Physiological Psychology, 1949, 42, 32-44.

Emmett-Oglesby, M. W., Lewy, A. J., Albert, L. H., \& Seiden, L. S. Role of lever responding and water presentation in altering rat brain catecholamine metabolism. Journal of Pharmacology and Experimental Therapeutics, 1978, 204, 406-415.

Glazer, H., \& WeISS, J., Long-term and transitory interference effects. Journal of Experimental Psychology: Animal Behavior Processes, 1976, 2, 191-201.

Hiroto, D., \& Seligman, M. E. P. Generality of learned helplessness in man. Journal of Personality and Social Psychology, 1975, 31, 311-327.

Maier, S. F., \& Testa, T. J. Failure to learn to escape in rats 
previously exposed to inescapable shock is partly due to associative interference. Journal of Comparative and Physiological Psychology, 1975, 88, 554-564.

McGaugh, J. L. Time-dependent processes in memory storage. Science, 1966, 153, 1351-1358.

Overmier, J. B. Interference with avoidance behavior: Failure to avoid traumatic shock. Journal of Experimental Psychology, $1968,78,340-343$.

Overmier, J. B., \& Seligman, M. E. P. Effects of inescapable shock upon subsequent escape and avoidance learning. Journal of Comparative and Physiological Psychology, 1967, 63, 18-33.

Padilla, A. M. Effects of prior and interpolated shock exposures on subsequent avoidance learning by goldfish. Psychological Reports, 1973, 31, 451-456.

Porsolt, R. D., Anton, G., Blavet, N., \& Jalfre, M. Behavioral despair in rats. A new model sensitive to antidepressant treatment. European Journal of Pharmacology, 1978, 47, 379-391.

Seiden, L. S., MacPhail, R. C., \& Emmett-Oglesby, M. W. Catecholamines and drug-behavior interactions. Federation Proceedings, 1975, 34, 1823-1831.
Seligman, M. E. P. Helplessness: On depression development and death. San Francisco: Freeman, 1975.

Seligman, M. E. P., \& Maier, S. F. Failure to escape traumatic shock. Journal of Experimental Psychology, 1967, 74, 1-9.

Turner, S., Sechner, J., \& Liebelt, R. Sensitivity to electric shock after ventromedial hypothalamic lesions. Experimental Neurology, 1967, 19, 236-244.

Weiss, J. B., Glazer, H. I., \& Pohorecky, L. A. Coping behavior and neurochemical changes: An alternative explanation for the "learned helplessness" experiments in animal models. In G. Serban \& A. King (Eds.), Human psychobiology. New York: Plenum Press, 1976.

Weiss, J. M., Stone, E. A., \& Harrell, N. Coping behavior and brain norepinephrine. Journal of Comparative and Physiological Psychology, 1970, 72, 153-160.

WeLKe R, R. L. Acquisition of a free operant appetitive response in pigeons as a function of prior experience with response independent food. Learning and Motivation, 1976, 7, 394-405.

(Received for publication February 9, 1979; revision accepted January 30,1980 .) 